\title{
Analysis and Discussion on the Design of Green Super High-rise Civil Buildings in Huangshan
}

\author{
Liu Jun ${ }^{1}$, Zhang Jinfeng ${ }^{1}$, Tu Qian ${ }^{2}$, Hu Haowei ${ }^{3}$, Shui Taotao ${ }^{3}$ \\ ${ }^{1}$ Stare Grid Anhui Electric Power Co., Ltd., Hefei, Anhui 230022, P.R. China; \\ ${ }^{2}$ State Grid Anhui Electric Power Co., Ltd. Construction Company, Hefei, Anhui 230071, P.R. China; \\ ${ }^{3}$ Anhui Jianzhu University, BIM Engineering Center of Anhui Province, Hefei, Anhui 230061, P.R. China
}

\begin{abstract}
With the accelerating urbanization process and the development of the construction industry, the role of green building design in architectural design is constantly reflected. The comprehensive implementation of green building is an important measure to promote China's energy-saving emission reduction and low-carbon city strategy. However, there are relatively few cases in which green building design is applied to super high-rise civil buildings, and in-depth research and data analysis must be carried out. The design points in green super high-rise civil buildings in Huangshan area were briefly summarized, and the actual cases of a green super high-rise civil building design in Huangshan City were analyzed, which is conducive to laying the foundation for the application of green building design to super high-rise civil buildings.
\end{abstract}

\section{Introduction}

With the continuous advancement of China's urbanization and modernization process and the rapid development of the construction industry, super high-rise buildings are increasingly favored by many developers due to their advantages of resource integration and intensive use. Compared with ordinary high-rise buildings, super high-rise buildings have unparalleled practical significance because of their overwhelming advantages in maximizing the use of land and energy. At present, China's super high-rise buildings continue to rise, mature and create new records. In essence, super high-rise buildings have obvious advantages for land use, resource sharing, efficiency of work and life, and urban modernization. This is an ecological existence ${ }^{[1]}$. However, some of its drawbacks ${ }^{[2]}$ cannot be ignored, such as high cost and management costs, high building energy consumption, closed internal environment of the building, and affecting the urban environment. Therefore, the design of green super high-rise civil buildings is the only way to sustainable development. Super high-rise civil buildings are one of the most up-to-date technical achievements of mankind. They should create and explore a more environmentally friendly and comfortable living environment for human beings. We should put forward China's own innovative ideas and development concepts, and adopt a people-oriented, green and sustainable architectural concept as a new goal which contributes to our sustainable development strategy.

There are few cases of domestic green super high-rise civil buildings. For example, Zhou Quan combined with actual cases to analyze the design points of green super high-rise buildings in Guangzhou ${ }^{[3]}$; Zheng Jianjiao studied the application of green building technology in super high-rise buildings in Shenzhen ${ }^{[4]}$; Li Shuangzhe discussed a green design strategy for the sustainable development of super high-rise buildings ${ }^{[5]}$. Although the above research has carried out a certain degree of analysis and discussion on the design of green super high-rise buildings, some scholars have given some suggestions for the design of green super high-rise buildings in specific regions. However, on the whole, there is no mature theoretical system for green super high-rise building design, which makes it impossible to fully reflect its value in specific engineering design and project implementation. Therefore, it is necessary to conduct more research and analysis on the application cases of green super high-rise civil buildings. By the case to provide a comprehensive and effective strategy for the sustainable development of super high-rise buildings through reasonable green building design means. This article starts from the design points of green super high-rise civil buildings in the Huangshan area, analyzes the actual local cases and proposes some design suggestions from the perspective of green buildings.

\section{Overview of Green Super High-rise Civil Building Design}

\subsection{Green super high-rise civil building definition}

According to the definition of "Green Building Evaluation Standard" GB/T 50378 ${ }^{[6]}$, green building refers to maximizing resource conservation (energy 
saving, land saving, water saving, material saving), environmental protection, pollution reduction. It provides people with a healthy, adaptable and efficient use of space, a building that is in harmony with nature. Green super high-rise civil buildings are based on this, compared with conventional super high-rise buildings, can significantly reduce energy consumption, improve indoor environmental quality, reduce environmental impact on surrounding cities, efficient and stable and low-carbon operation, and integrated Super high-rise building with its own characteristics and a sustainable concept of civil architecture.

Considering the necessity of applying green building design to the development of super high-rise buildings, the Ministry of Housing and Urban-Rural Development compiled the "Technical Rules for the Evaluation of Green Super-tall Buildings" " ${ }^{[7]}$ in 2012 as a supplement to the "Green Building Evaluation Standards". However, the technical rules are aimed at the evaluation of green super high-rise public buildings. The evaluation of green super high-rise civil buildings is mainly based on the "Green Building Evaluation Standards", which still cannot fully reflect the technical characteristics of super high-rise civil buildings.

\subsection{Green super high-rise civil building design technology system}

The sustainability of green super high-rise civil building technology design system is mainly reflected in the following aspects ${ }^{[3]}$ :

(1) Land and outdoor environment: including technical measures to reduce various types of environmental pollution, implement three-dimensional greening, rationally organize site traffic, improve space utilization, control nearby wind environment, and select abandoned sites.

(2) Energy conservation and energy utilization: including building energy comprehensive planning, envelope structure, air conditioning system, window wall design, renewable energy and other technical measures.

(3) Water conservation and water resources utilization: including water supply and drainage systems, water-saving technologies, water-saving irrigation, and utilization of recycled water.

(4) Utilization of materials and materials: including technical measures to optimize civil construction, use of reusable or recycled building materials, and classification and recovery of solid waste.

(5) Indoor environmental quality: including technical measures such as indoor sound insulation, lighting, decorative materials, air quality, and spatial layout design.

\section{Design points of green super high-rise civil buildings in the Huangshan area}

For the construction profession, the above-mentioned green super high-rise civil building technical system mainly involves two aspects of land saving and energy saving. The land saving is to create a good outdoor wind environment by using reasonable architectural layout and landscape design in the planning stage. Natural ventilation, energy saving is the reduction of building energy consumption with thermal performance optimization and enclosure design.

\subsection{Architectural layout design}

For super high-rise buildings, if the design is improper, it is easy to form a regenerative wind environment around the super high-rise buildings, resulting in a strong gust of wind, which brings great inconvenience to pedestrians and even affects the safety of pedestrians. Therefore, both the "Green Building Evaluation Standard" and the "Green Super High-rise Building Evaluation Technical Rules" clearly indicate that the wind speed around the building should not exceed $5 \mathrm{~m} / \mathrm{s}$ at a height of $1.5 \mathrm{~m}$ to ensure normal outdoor activities. On the other hand, when the outdoor wind speed is lower than $1 \mathrm{~m} / \mathrm{s}$, there will be poor ventilation, and it will evolve into a windless zone and a vortex zone in the surrounding area of the building, hindering the dissipation of pollutants and outdoor heat dissipation, especially in the summer. In order to make a good ventilation corridor in the city to reduce the urban local geothermal island effect and improve the residents' thermal comfort, the building should be rationally planned and layout. Therefore, it is necessary to combine the local wind and climate characteristics of Huangshan City to create a better outdoor wind environment through reasonable architectural layout.

Through the statistical analysis of the long-term meteorological data of Huangshan area, the dominant wind direction of Huangshan City is southwest wind, and the wind frequency of northeast wind and southeast wind is relatively high. The average annual wind speed is $3.4 \mathrm{~m} / \mathrm{s}$ and the maximum wind speed is $19.5 \mathrm{~m} / \mathrm{s}$ as shown in Figure 1. Specifically, the summer and transition seasons are dominated by southwesterly winds, and the secondary dominant winds are northeast and southwest winds. In winter, northwest winds and southeast winds prevail. The average wind speed of northwest winds is significantly higher than other wind directions. In combination with the above-mentioned wind climatic characteristics of Huangshan City, considering the need to promote natural ventilation in summer and the need to consider wind protection in winter. When the building group adopts the determinant layout, it should be oriented in the southeast direction, so that the upstream buildings in winter can play a better windproof role, and in the summer as a ventilation corridor.

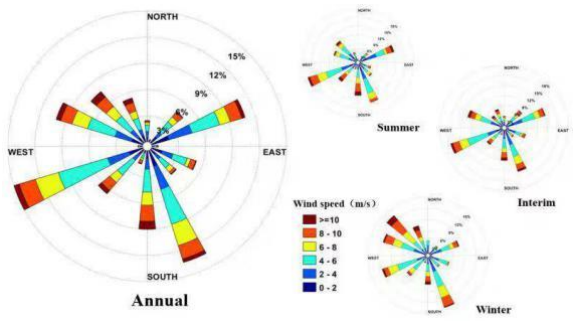

Figure 1. Huangshan city wind rose map 


\subsection{Building envelope design}

Huangshan City is located in the mid-latitude area, which belongs to the subtropical monsoon humid climate. The four seasons are distinct, the spring and autumn are short and the winter and summer are long. The rainfall is abundant. The rains are hot from March to July. The light and heat are complementary in July and October. The sunshine is less, the clouds are more, and higher humidity. The temperature in the spring is low, the rain is continuous, and the precipitation is concentrated in April-May. In summer, the temperature is high and the precipitation is high. During the rainy season, the precipitation is concentrated, the flood is frequent, and the high temperature is easy to drought. In the autumn, the temperature is significantly lower, the precipitation is less, and there is often autumn drought; the winter climate is dry and cold, often with rain and snow. According to the building thermal zoning in the "Code for Thermal Design of Civil Buildings" (GB50176-93), Huangshan City belongs to the hot summer and cold winter zone. The average annual temperature is $15.4^{\circ} \mathrm{C}$, and the average temperature of the hottest month in July is $26.2^{\circ} \mathrm{C}$. The average temperature in January is $4.1^{\circ} \mathrm{C}$.

In view of the above-mentioned climatic characteristics, the building envelope structure in the Huangshan area should be based on summer heat insulation, supplemented by winter cold design. Super high-rise buildings are usually designed with glass curtain wall or large window wall as the main par. At the same time, the application of external shading is limited for safety reasons. In addition, the intensity and time of solar radiation received by super high-rise buildings are significantly higher than that of buildings below the average canopy height of cities. The construction, which also caused greater energy consumption and air conditioning load in super high-rise buildings compared to ordinary buildings. Therefore, it is necessary to strengthen the thermal insulation performance of the glass curtain wall and the external wall in the architectural design stage, increase the airtightness of the building, and improve the shading effect by combining the self, outer and inner sunshade to achieve the purpose of effectively reducing the air conditioning energy consumption in summer.

\section{Case analysis}

A case of a residential project in Huangshan City was analyzed. Two high-rise residential buildings in the project are more than 100 meters (101.2 meters), which belongs to the category of super high-rise civil buildings. The project fully adopted the green building technology. According to the "Green Building Evaluation Mark Management Measures" and "Anhui Green Building Evaluation Mark Implementation Rules (Trial)" and related regulations, the Green Building Review of the Anhui Provincial Housing and Construction Department was approved in 2017.

\subsection{Project Overview}

The residential project is located in the eastern urban area of Tun xi District, Huangshan City, with a total site area of approximately $41,827.42 \mathrm{~m} 2$ and a total construction area of $108,580.84 \mathrm{~m} 2$. The main construction contents of the project include: 2 super high-rise residential buildings (32F), 8 multi-storey residential buildings (6 8F) and 1 neighborhood center $(2 \mathrm{~F})$, and supporting commercial buildings, property houses, power distribution rooms, underground Garage and other related facilities. The project is planned according to the existing site conditions: the main entrance and exit of the community is set in the new district road, the sub-entry entrance and the entrance and exit of the basement are set in Xinyuan East Road, and one entrance and exit of the basement is arranged on the northwest side of the plot to facilitate the access of vehicles and residents. 1\# 11\# Building adopts determinant layout, both north and south orientation. Two super high-rise residential buildings (9\#, $10 \#)$ are arranged on the west side of the plot, and the whole community is carried out with the central landscape belt, group greening and community roads. Divided and connected, the operational neighborhood center is arranged along the new district road, and the power distribution room is set on the west side of the plot. The general plan layout and renderings of the project are shown in Figure 2.

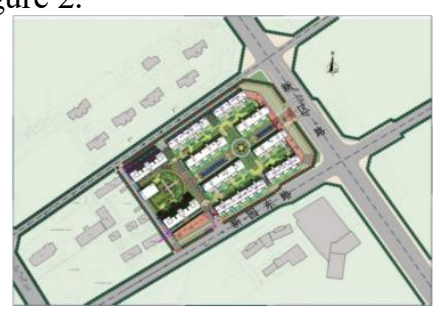

(a) General layout

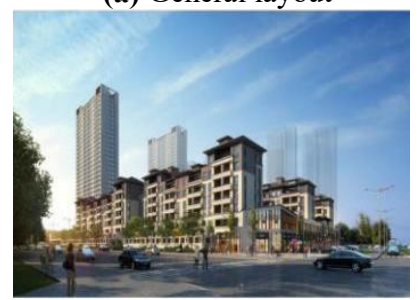

(b) Project effect diagram

Figure 2. General layout and project effect diagram

\section{2 analysis of outdoor wind environment}

At the planning and design stage, this residential project improves the ventilation effect of pedestrian height through rational building layout and site utilization. Through the numerical simulation of outdoor wind environment under the dominant wind direction in different seasons in Huangshan city, the average wind speed in the pedestrian area around residential buildings is generally between $1.1 \mathrm{~m} / \mathrm{s} \sim 2.5 \mathrm{~m} / \mathrm{s}$, which meets the requirements of the code. There are wind shadow areas in some areas. The overall outdoor wind environment is good. Specific analysis is as follows:

(1) the dominant wind direction in summer (southwest) under the residential outdoor environment as 
shown in Figure 3(a), the wind can be seen from the graph construction surrounding area overall air distribution is relatively uniform, most of the regional wind speed $1.6 \mathrm{~m} / \mathrm{s} \sim 2.5 \mathrm{~m} / \mathrm{s}$, formed a relatively good ventilated corridor between buildings, can effectively eliminate the heat and pollutants of living area so as to improve the thermal comfort and air quality of community professionals.

(2) the outdoor wind environment of residential areas under the dominant wind direction (northwest wind) in winter is shown in Figure 3(b). It can be seen that the overall wind speed in the surrounding area is significantly lower than that in summer, and the wind speed in most areas is between $1.1 \mathrm{~m} / \mathrm{s}$ and $1.7 \mathrm{~m} / \mathrm{s}$.

(3) residential narrow duct is formed between the upstream building common high wind speed areas as shown in Figure 3(b), if the area is set to the village entrance will give big inconvenience caused by residents in the project, the major residential gateway and time entry set respectively in settlements in the east new district road and south of the new garden east road, and the winter under the dominant wind direction of the wind speed is larger set to basement entrances, is effective to optimize the above disadvantages.

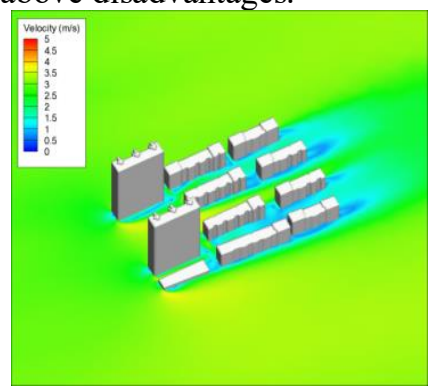

(a) Summer

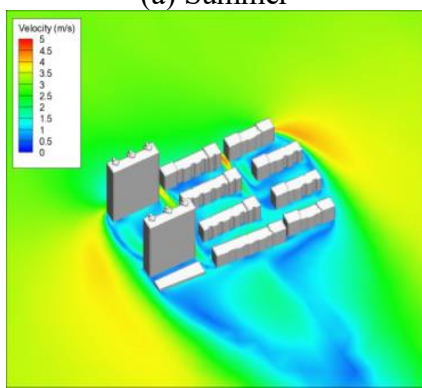

(b) Winter

Figure 3. Outdoor wind environment of residential areas under the dominant wind direction

\subsection{Analysis of building energy consumption}

The project pays great attention to the thermal insulation performance of the wall in the design of the envelope structure. The main part of the building exterior wall is made of polymer plaster anti-cracking mortar $(5.0 \mathrm{~mm})+$ rock wool board $2(30.0 \mathrm{~mm})+$ cement mortar $(10.0 \mathrm{~mm})$ + Reinforced concrete $(200.0 \mathrm{~mm})+$ lime cement mortar $(15.0 \mathrm{~mm})$ structure, heat transfer coefficient $1.08 \mathrm{~W} /$ $(\mathrm{m} 2 . \mathrm{K})$. The outer window with heat-dissipating aluminum alloy ordinary hollow glass window $(5+9 A+5)$. The heat transfer coefficient is $3.20 \mathrm{~W} / \mathrm{m} 2$.K.The self-shading coefficient is 0.89 , and the airtightness is 6 . In addition, external thermal insulation is applied to each thermal bridge, column and floor to ensure that the heat transfer coefficient is lower than $1.5 \mathrm{w} /\left(\mathrm{m}^{2} * \mathrm{~K}\right)$ stipulated in Anhui province residential building energy saving design standard.

In order to verify that the building meets the energy-saving requirements of the "Environmental Design Standard for Residential Buildings in Anhui Province" (DB34/1466-2011), the annual energy consumption of each building is calculated according to the calculation method of the comprehensive energy-saving index of building energy provided by the "Environmental Design Standard for Residential Buildings in Anhui Province". The calculation is performed and the calculation conditions are as follows:

(1) The calculated indoor temperature in summer and winter buildings is $26^{\circ} \mathrm{C}$ and $18^{\circ} \mathrm{C}$ respectively (all day).

(2) Calculation period of air conditioning set from June 15th to August 31st, and the heating calculation period is set from December 1st to February 28th, the following year.

(3) The meteorological data of the local typical meteorological year in Huangshan are used as the outdoor meteorological calculation parameters.

(4) During the calculation period of heating and air conditioning, take the number of air changes once per hour.

(5) Air conditioning and heating equipment are domestic air source heat pump air conditioners, and the rated energy efficiency ratio during refrigeration and heating is 2.3 and 1.9 respectively 。

(6) The average indoor heat gain is $4.3 \mathrm{~W} / \mathrm{m} 2$. The parameters of other buildings are based on the parameters provided by the Anhui Province Residential Building Energy Efficiency Design Standard (DB34/1466-2011). Table 1 and Table 2 respectively show the annual energy consumption calculation results of the project $10 \#$ building and the reference building, and the energy consumption comparison analysis chart is shown in Figure 4. It can be seen that the annual energy consumption per unit area of the designed building is less than the annual energy consumption per unit area of the reference building, and meets the energy-saving requirements of the "Energy Design Standard for Residential Buildings in Anhui Province".

Table 1. Annual energy consumption calculation results of project 10\#

\begin{tabular}{lcc}
\hline Energy type & $\begin{array}{l}\text { Energy } \\
\text { consumption } \\
(\mathbf{k W h )}\end{array}$ & $\begin{array}{l}\text { Energy } \\
\text { consumption per } \\
\text { unit } \\
\text { area(kWh/m2) }\end{array}$ \\
\hline $\begin{array}{l}\text { Air conditioning power } \\
\text { consumption }\end{array}$ & 46164 & 7.91 \\
$\begin{array}{l}\text { Heating power } \\
\text { consumption } \\
\text { total }\end{array}$ & 131840 & 22.59 \\
\hline
\end{tabular}


Table 2. Calculation results based on annual energy consumption of buildings

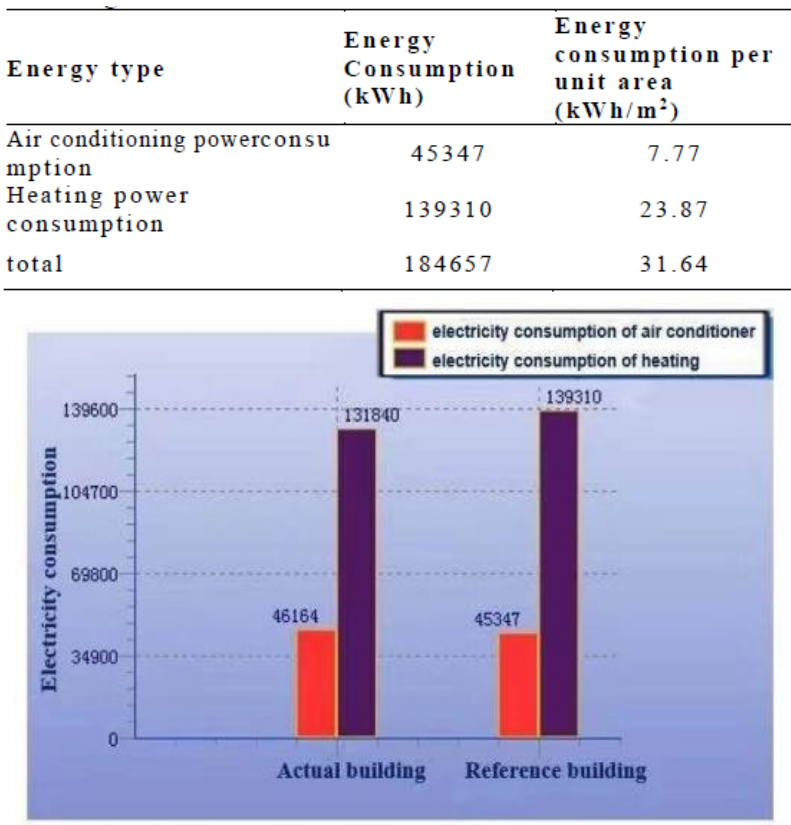

Figure 4. Comparison of energy consumption analysis

\section{Conclusion}

Green building is the development direction of green energy-saving buildings in the future. High-efficiency energy-saving standards and the use of new materials and renewable energy can reduce environmental pollution, promote industrial upgrading, promote industrial transformation and achieve sustainable development goals. This paper introduces some design points of green super high-rise civil buildings in Huangshan City, and probes into the application of green building design in practical cases. The project uses effective green design methods and technical applications to improve the outdoor wind environment of buildings and achieve energy saving in buildings. Promoting energy saving and green development in super high-rise civil buildings is of great practical significance to the construction of green and low-carbon buildings and the construction of green and ecological urban areas.

\section{References}

1. Liu Lei. The Research on Green Design Strategies of Ultra High-rise Building [D]. Tianjin University, 2014.

2. Sun Zhong yuan. Literature review of green super high-rise building strategy [J]. Green environmental building materials, 2018 (09): 193-194.

3. Zhou Quan, Zhang Qi, Liu Junxiong, Fang Enquan, Yu Kailun Emphases and Instance Analysis of Ultra High-rise Green Buildings' Architectural Design in Guangzhou [J]. Building Energy Conservation, 2017, 45(03): 88-91.

4. Zheng Jianjiao Chen Yiming, Chen Cheng, et al.
Green Design Practice and Revelation of Super High-rise Building in Shenzhen City [J]. Architectural Technology Development, 2018(11): 115-116.

5. Li Shuangzhe. Design of Super High-rise Buildings Based on Green Ecological Sustainable Development Goals [J]. Building Energy Conservation, 2018, 46(09): 22-27.

6. GB / T 50378-2014, Standard-Assessment Standard for Green Building [S].

7. Li Hongjun, Fan Hongwu, Han Jihong, Song Ling. Revision ideas and key points of green super high-rise building evaluation technical rules [J]. Construction Technology, 2016 (10): 20-21. 